\title{
Leaf size, specific leaf area and microhabitat distribution of chaparral woody plants: contrasting patterns in species level and community level analyses
}

\author{
D. D. Ackerly · C. A. Knight · S. B. Weiss $\cdot$ K. Barton \\ K. P. Starmer
}

\begin{abstract}
We examined variation in leaf size and specific leaf area (SLA) in relation to the distribution of 22 chaparral shrub species on small-scale gradients of aspect and elevation. Potential incident solar radiation (insolation) was estimated from a geographic information system to quantify microclimate affinities of these species across north- and south-facing slopes. At the community level, leaf size and SLA both declined with increasing insolation, based on average trait values for the species found in plots along the gradient. However, leaf size and SLA were not significantly correlated across species, suggesting that these two traits are decoupled and associated with different aspects of performance along this environmental gradient. For individual species, SLA was negatively correlated with species distributions along the insolation gradient, and was significantly lower in evergreen versus deciduous species. Leaf size exhibited a negative but non-significant trend in relation to insolation distribution of individual species. At the community level, variance in leaf size increased with increasing insolation. For individual species, there was a greater range of leaf size on south-facing slopes, while there was an absence of small-leaved species on northfacing slopes. These results demonstrate that analyses of plant functional traits along environmental gradients based on community level averages may obscure important aspects of trait variation and distribution among the constituent species.
\end{abstract}

Keywords Elevation - Gradient analysis · Insolation . Mediterranean type ecosystem $\cdot$ Deciduous vs evergreen species

\section{Introduction}

The relationship between plant form and environment has played a central role in plant ecology and the study of convergent evolution (e.g., Mooney 1977; Box 1981). Leaf traits play a particularly important role in carbon assimilation, water relations and energy balance. Leaf size and specific leaf area (SLA, the ratio of leaf area to mass) decline along gradients of decreasing moisture and/or nutrient availability (Schimper 1903; Hamann 1979; Dolph and Dilcher 1980; Givnish 1984; Skarpe 1996; Cunningham et al. 1999; Fonseca et al. 2000). These patterns are broadly consistent with our understanding of the functional significance of these traits. SLA is negatively correlated with leaf life span and assimilation rates, and is generally lower in leaves of evergreen compared to deciduous species (Reich et al. 1997). Lower SLA (due to thicker and/or more dense leaves) contributes to long leaf survival, nutrient retention, and protection from desiccation (Mooney and Dunn 1970a). Small leaf size reduces boundary layer resistance, and helps to maintain favorable leaf temperatures and higher photosynthetic water-use efficiency under the combination of high solar radiation and low water availability (or low stomatal conductance) (Parkhurst and Loucks 1972; Givnish and Vermeij 1976). As leaf size and SLA usually change in parallel, it has been suggested that these traits represent two facets of a functional strategy associated with low water and/or nutrient availability (e.g., Mooney and Dunn 1970a; Parsons 1976; but see Grubb 1998; Cunningham et al. 1999). However, studies of leaf structure in relation to environmental factors have generally examined average leaf traits at the community level (see citations above). At the species level, comparative studies of woody plants from a range of environments suggest that leaf size and SLA may not be closely linked 
(Ackerly and Reich 1999; Fonseca et al. 2000). Few studies have examined leaf traits in relation to the distribution of individual species along environmental gradients (e.g., Ehleringer et al. 1981), and addressed the relationship between the attributes of individual species and the overall characteristics of communities.

Mediterranean-type ecosystems provide an excellent system in which to examine these relationships. Mediterranean climates, which occur in California, Chile, South Africa, Australia and the Mediterranean basin, are characterized by cool wet winters and hot dry summers, during which low water availability severely limits carbon gain. The woody vegetation in these regions (known as chaparral in California) is dominated by evergreen shrub species with small, sclerophyllous (tough or leathery) leaves (Cooper 1922; Specht 1969; Mooney and Dunn 1970b). Sclerophyllous leaves are almost always described as small and thick (e.g., Schimper 1903), and the two traits are linked as part of the drought tolerance strategy of the evergreen chaparral species (Mooney and Dunn 1970a; Parsons 1976). The functional role of the traits is supported by comparisons conducted across broad and fine-scale environmental gradients. At a regional scale, evergreen species predominate in the chaparral vegetation, with increasing frequency of droughtdeciduous species in the xeric coastal sage scrub and winter-deciduous taxa in the cooler montane woodlands (Mooney et al. 1970; Parsons and Moldenke 1975). Across sites within the chaparral, leaf size increases with mean precipitation (Poole and Miller 1981).

On a local scale, topography and elevation strongly influence microclimate and the distribution of plant species and their associated attributes (Cooper 1922; Boyko 1947; Parsons 1976; Armesto and Martínez 1978; Miller et al. 1983). Incident solar radiation (hereafter, insolation) is higher on south-facing slopes (in the Northern Hemisphere), resulting in higher air and soil temperatures (Geiger 1965; Martínez and Armesto 1983; Nobel and Linton 1997). Soil moisture is generally higher on north-facing slopes, especially in the organic and upper soil layers (e.g., Cooper 1922; Miller 1947; Nobel and Linton 1997; but see Ng and Miller 1980). Temperature and moisture differences may alter nutrient mineralization and availability on north- versus south-facing slopes (Miller 1979). The drier conditions on south-facing slopes may also lead to higher fire-frequency (Kutiel 1997; but see Keeley et al. 1999), and increased solar radiation in the post-fire environment may influence seedling establishment, resprout success and subsequent species regeneration patterns (Kutiel 1997). Species distributions and leaf traits have been examined in relation to aspect and altitude in California and Chile (Parsons 1976; Armesto and Martínez 1978). In both communities, summer deciduous taxa predominate on more xeric aspects (ridge tops and equatorial slopes), paralleling the geographic trend towards deciduousness in the coastal sage community (Parsons and Moldenke 1975). In California, small-leaved species also predominate on ridge tops and south-facing slopes, primarily due to the abun- dance of the needle-leaved Adenostoma fasciculatum. In both regions large-leaved species occurred in the more mesic pole-facing slopes and ravines. These studies demonstrate that north- and south-facing slopes in the chaparral are clearly differentiated in terms of species composition, leaf traits and vegetation structure. However, as in studies across broad climatic gradients, the analyses of leaf trait variation in the chaparral are based on average characteristics at the community level and the individual distribution patterns of shrub species along topographic gradients have not been carefully evaluated (for analyses of geographic distributions with respect to climate in chaparral and coastal sage scrub, see Westman 1981, 1991; Franklin 1998).

In this study, we quantified the distributions of woody plant species across gradients of exposure and elevation in a central California chaparral community. Based on these data, we examined the distribution of leaf size and SLA at the community and individual species levels, and addressed the following questions: (1) Are there significant differences between communities on north- versus south-facing slopes in leaf size, SLA or leaf habit (evergreen vs deciduous)? (2) Are patterns at the community level paralleled by significant shifts in the distributions and leaf traits of individual species? (3) Are there changes in the range of leaf size or SLA (e.g., shifts in minima vs maxima) across environmental gradients? (4) Do shifts in community level trait distributions reflect correlated traits at the species level (see Fonseca et al. 2000; Mabry et al. 2000)?

\section{Materials and methods}

Site description and GIS analysis

The study was conducted at the Jasper Ridge Biological Preserve (JRBP), San Mateo Co., Calif. $\left(37.4^{\circ} \mathrm{N}, 122.25^{\circ} \mathrm{W}\right)$, located in the Mediterranean climate zone of coastal California. JRBP is located at $\sim 150 \mathrm{~m}$ a.s.l., with mean summer temperature of $20.1^{\circ} \mathrm{C}$, mean winter temperature of $9.2^{\circ} \mathrm{C}$, total annual precipitation of $622.5 \mathrm{~mm}$, and a dry season of approximately 6 months (May-October, precipitation $<50 \mathrm{~mm} / \mathrm{month}$ ). Distributions of woody plant species were sampled in a contiguous chaparral patch of 51 ha located on undulating topography with elevations between 62 and $210 \mathrm{~m}$ a.s.l. Soils in this area are derived from basaltic greenstones. The patch is intersected by several westward running drainages, resulting in a predominance of north- and south-, and to a lesser extent, west-facing aspects, with slopes between $5^{\circ}$ and $30^{\circ}$.

The JRBP Geographic Information System (GIS) contains information on slope, aspect, and elevation at a scale of $5 \mathrm{~m}$. The GIS base map was used to calculate potential diurnal insolation (PDI) and an index of local topographic position at each point (calculations were conducted in ArcInfo and ArcView software, ESRI, Redlands, Calif.). Topographic position was calculated as the elevation of each point minus the mean elevation in circles with radius 10, 20,50 and $100 \mathrm{~m}$ centered on that point. Positive values represent hill and ridge tops, while negative values represent valley bottoms. An insolation model (Hetrick et al. 1993) was used to predict PDI incident at each point based on slope, aspect and neighboring topography (see Weiss et al. 1993). For this study, estimates were obtained for the spring and fall equinoxes (which are equivalent) and the summer and winter solstices; mean PDI was calculated as the average of these four values. An annual 
average was used because plant performance, especially for evergreens, may be influenced by conditions in all seasons. Across all sites in the chaparral, mean values of PDI ranged from 5.1 to 18.7 $\mathrm{MJ} \mathrm{m}^{-2}$ day $^{-1}$, with higher values on south-facing slopes as expected.

\section{Species distributions}

The distributions of woody plant species (excluding vines) were assessed in June-July 1997. Seven transects were located across east-west ridge tops, intersecting a wide range of slope orientations. Transects were initiated at a predetermined location and direction without reference to plant communities or species distributions. Transects included 34-75 points, located at $4 \mathrm{~m}$ intervals, with a total of 311 points for the entire survey. The location of each point was recorded with a geographic positioning system receiver (Geoexplorer II, Trimble, Sunnyvale, Calif.), with differential correction to provide resolution of $<1 \mathrm{~m}$. At each point, the occurrence of all woody plant species in a $2 \mathrm{~m}$ diameter circle (area $=3.14 \mathrm{~m}^{2}$ ) was recorded on a four-point scale reflecting percent cover $(0,0 \% ; 1,1-33 \% ; 2,34-67 \% ; 3,68-100 \%)$. In addition, each species was recorded as either "canopy", if any plants were fully exposed to the sun, or "understory" if all individuals in the plot were shaded.

An analysis using canonical correspondence analysis (CCA, Jongman et al. 1995; Ter Braak and Smilauer 1998) indicated that species distributions were most strongly associated with PDI, and secondarily with elevation; the topographic position indices were not significant after elevation was taken into account (CCA results are available from the first author). Based on these results, direct gradient analysis (Whittaker 1967; Austin et al. 1990) was conducted by grouping plots into 13 equal interval categories of PDI and elevation and calculating frequency of occurrence and average percent cover (the sum of the relative cover values divided by total number of plots in that category) of each species for each category. The mean of the distribution of each species along the two gradients was calculated based on the value of PDI and elevation, weighted by species' relative cover, at each transect point. This mean value was used to represent the relative location of species distributions along the insolation and elevation gradients.

\section{Leaf functional traits}

Leaves were collected from six representative plants of each species in the same area as the transects, with two fully exposed leaves sampled from each plant. Leaf area was measured with a Li-Cor 3100 leaf area meter (Li-Cor, Lincoln, Neb.) and leaves were dried for $48 \mathrm{~h}$ at $65^{\circ}$ for determination of dry mass. Leaf size refers to average individual leaf area. SLA (area/mass, $\mathrm{mm}^{2} \mathrm{mg}^{-1}$ ) was calculated for individual leaves before calculating species averages. Species means were $\log _{10}$-transformed prior to analysis to improve normality, and to focus on relative variation among species and sites. Due to the large number of sample points (311 plots), we did not sample leaves from each species in each plot for measurement of leaf size and SLA. Thus, the results of our interspecific analyses do not take into account plasticity or genetic variation among individuals growing at different points along the gradient. We addressed this issue in two ways. First, for 18 of the species, we determined the GPS position and the corresponding PDI value of each plant used for sampling SLA, and tested whether the mean PDI of the SLA plants reflected the mean position of the species along our transects. Secondly, we assessed intraspecific variation in relation to PDI in the primary SLA data set, and in two independent samples. In an independent study of herbivory patterns (K. Barton, unpublished data), random samples of 10 leaves per plant were collected from 4-10 individuals per species distributed across the range of microsites in the study area; PDI values were obtained for each plant based on GPS locations. For the primary SLA sample and the 'herbivory' study, analysis of covariance, with species as a fixed factor and PDI as the covariate, was used to test for intraspecific plasticity in SLA with respect to
PDI. Finally, samples of 10 sun leaves of Prunus ilicifolia, which occurs across a particularly broad range of environments, were collected at the extremes of the PDI gradient to test for intraspecific variation in SLA.

Trait distributions along environmental gradients

Variation in leaf size and SLA in relation to gradients of PDI and elevation was analyzed at the species and community levels. Across species, linear regression was used to test whether average leaf traits varied as a function of species' distribution means, derived from direct gradient analysis, along the PDI and elevation gradients. At the community level, the 311 plots were grouped into 13 equal interval categories along each gradient, and presence/absence and average cover based on all plots within each category were tabulated for each species. For each of the 13 categories, the average value of each leaf attribute was calculated from the species values, either unweighted (based on presence/absence) or weighted by average cover values to reflect relative dominance of the species along the gradient. Relative variation was determined as the standard deviation of species values for each category along the insolation gradient.

\section{Results}

\section{Species distributions}

Twenty-two species of shrubs and small trees were encountered in the 311 transect plots (Table 1). The two most common species were Prunus ilicifolia and Adenostoma fasciculatum, encountered in $68 \%$ and $60 \%$ of the plots, respectively. The average number of species per plot $\left(3.14 \mathrm{~m}^{2}\right.$ ) was 2.9 (range 1-6), and mean cover values on a scale of $0-3$ averaged 1.6 (corresponding to cover of $1-33 \%$ in plots where a species was present). Mean cover was greater than 2 (i.e. $>34 \%$ ) for only two species: A. fasciculatum, which is dominant on southfacing slopes, and Quercus agrifolia, which occurs as occasional small trees that completely covered our sample plots.

Distribution patterns with respect to PDI are illustrated for selected species in Fig. 1. The mean of the species distributions on the PDI gradient (indicated by arrows in Fig. 1) ranged from $7.5 \mathrm{MJ} \mathrm{m}^{-2}$ day $^{-1}$ in Solanum umbelliferum to $16.8 \mathrm{MJ} \mathrm{m}^{-2}$ day $^{-1}$ in Artemisia californica. Mean elevation values ranged from $131 \mathrm{~m}$ a.s.l. in $S$. umbelliferum to $170 \mathrm{~m}$ a.s.l. in Lepechinia calycina (Table 1). There was a positive correlation between species mean positions on the insolation and elevation gradients, primarily reflecting the distribution patterns of deciduous species (Fig. 2). Mean locations of deciduous versus evergreen species were not significantly different on either gradient, and the species at the extremes of both gradients were deciduous (Fig. 2).

The strong transition between the communities of north- and south-facing slopes was apparent in the shift in species composition between 12 and $14 \mathrm{MJ} \mathrm{m}^{-2}$ day $^{-1}$ (e.g., Toxicodendron diversilobum, A. fasciculatum, Ceanothus cuneatus; Fig. 1). For L. calycina, the peak in its distribution was at this intermediate level, corresponding to intermediate PDI values on hilltops where this species 
Table 1 List of woody plant species encountered in this study (nomenclature follows Hickman 1993), with functional traits and results of direct gradient analyses. Species are arranged in order of insolation distribution values. [Habit: $E$ evergreen, $D$ deciduous;
Freq number of plots out of 311 in which species was encountered; Cover mean cover in plots where the species occurred (1, $1-33 \% ; 2,33-66 \% ; 3,67-100 \%)$. Measurements of direct gradients and functional traits are described in text]

\begin{tabular}{|c|c|c|c|c|c|c|c|}
\hline \multirow[t]{2}{*}{ Species } & \multirow[t]{2}{*}{ Habit } & \multirow[t]{2}{*}{ Freq } & \multirow[t]{2}{*}{ Cover } & \multicolumn{2}{|l|}{ Direct gradient } & \multicolumn{2}{|l|}{ Functional traits } \\
\hline & & & & $\begin{array}{l}\text { Insolation } \\
\left(\mathrm{MJ} \mathrm{m}^{-2} \mathrm{day}^{-1}\right)\end{array}$ & $\begin{array}{l}\text { Elevation } \\
\text { (m) }\end{array}$ & $\begin{array}{l}\text { Specific leaf area } \\
\left(\mathrm{mm}^{2} \mathrm{mg}^{-1}\right)\end{array}$ & $\begin{array}{l}\text { Leaf size } \\
\left(\mathrm{mm}^{2}\right)\end{array}$ \\
\hline Solanum umbelliferum & $\mathrm{D}$ & 2 & 1.0 & 7.5 & 131 & 12.5 & 518 \\
\hline Salix spp & $\mathrm{D}$ & 3 & 1.0 & 8.8 & 143 & 8.53 & 292 \\
\hline Holodiscus discolor & $\mathrm{D}$ & 20 & 1.5 & 10.5 & 133.9 & 12.8 & 755 \\
\hline Rhamnus californica & $\mathrm{E}$ & 9 & 1.0 & 10.8 & 163.5 & 13.5 & 1,698 \\
\hline Toxicodendron diversilobum & $\mathrm{D}$ & 63 & 1.7 & 10.9 & 148.9 & 12.6 & 6,457 \\
\hline Dirca occidentalis & $\mathrm{D}$ & 44 & 1.2 & 11.6 & 165.5 & 17.5 & 1,259 \\
\hline Prunus ilicifolia & $\mathrm{E}$ & 211 & 1.6 & 12.2 & 157.9 & 6.64 & 545 \\
\hline Ribes californicum & $\mathrm{D}$ & 15 & 1.0 & 12.9 & 158.6 & 10.8 & 223 \\
\hline Baccharis pilularis & $\mathrm{E}$ & 9 & 1.1 & 13.6 & 155.6 & 9.33 & 181 \\
\hline Heteromeles arbutifolia & $\mathrm{E}$ & 90 & 1.2 & 13.8 & 163.2 & 4.84 & 1,778 \\
\hline Ceanothus oliganthus ssp sorediatus & $\mathrm{E}$ & 2 & 1.0 & 14.1 & 164 & 8.30 & 278 \\
\hline Cercocarpus betuloides & $\mathrm{E}$ & 22 & 1.9 & 14.3 & 153.4 & 7.18 & 242 \\
\hline Mimulus aurantiacus & $\mathrm{E}$ & 34 & 1.1 & 14.4 & 158.0 & 8.93 & 194 \\
\hline Quercus agrifolia & $\mathrm{E}$ & 7 & 2.1 & 14.6 & 149.3 & 5.11 & 908 \\
\hline Lepechinia calycina & $\mathrm{D}$ & 40 & 1.2 & 14.7 & 170.0 & 10.0 & 1,660 \\
\hline Rhamnus crocea & $\mathrm{E}$ & 17 & 1.5 & 14.7 & 162.8 & 8.13 & 74 \\
\hline Ceanothus cuneatus & $\mathrm{E}$ & 83 & 1.6 & 15.2 & 157.1 & 4.40 & 177 \\
\hline Sambucus mexicana & $\mathrm{D}$ & 5 & 1.8 & 15.2 & 139.6 & 10.0 & 7,413 \\
\hline Lotus scoparius & $\mathrm{D}$ & 3 & 1.0 & 15.3 & 166 & 10.4 & 16 \\
\hline Adenostema fasciculatum & $\mathrm{E}$ & 188 & 2.3 & 15.7 & 166.4 & 3.52 & 7 \\
\hline Eriodictyon californicum & $\mathrm{E}$ & 7 & 1.1 & 16.6 & 161 & 5.61 & 2,570 \\
\hline Artemisia californica & $\mathrm{D}$ & 24 & 1.5 & 16.8 & 151.4 & 10.5 & 51 \\
\hline
\end{tabular}

Fig. 1A-H Distribution of selected species along the gradient of potential diurnal insolation (PDI). Moving from low to high values corresponds to north- vs south-facing slopes, respectively. Species are arranged $(\mathbf{A}-\mathbf{H})$ in order of increasing values for mean position along the PDI gradient, indicated by the arrows (see values in Table 1, Fig. 2). For Prunus ilicifolia and Heteromeles arbutifolia $(\mathbf{E}, \mathbf{F})$, the upper distribution (solid circles) shows the overall frequency of occurrence for each species, and the lower distribution (open circles) shows the frequency of occurrence in plots where plants were only recorded in the understory $(U)$; the difference between these values is the frequency of occurrence in the canopy or canopy and understory $(C)$
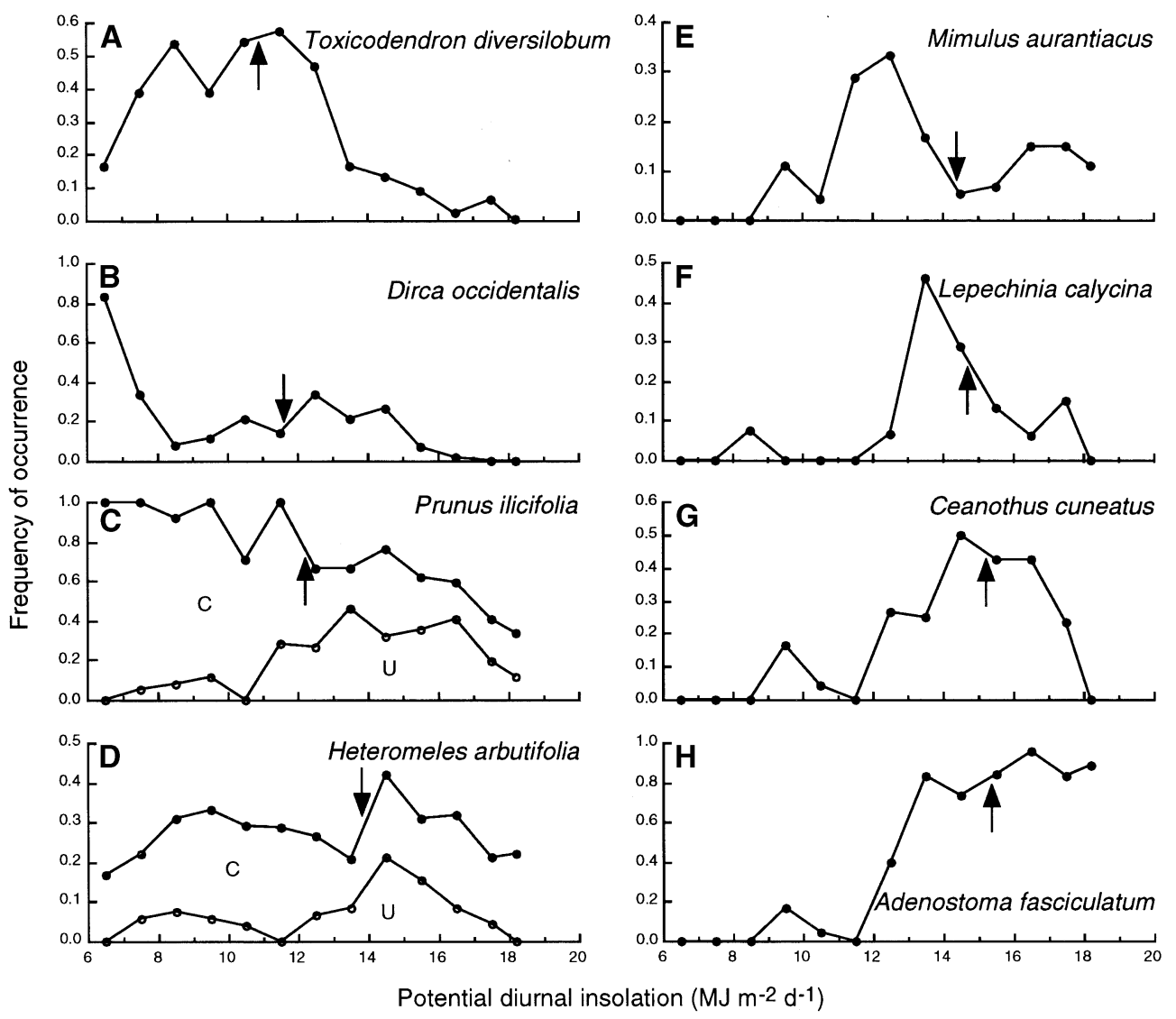
was locally abundant. The broadest distributions were observed in P. ilicifolia and Heteromeles arbutifolia. These two species were present only in the understory in a large number of plots. In both species, mean PDI was greater for the distributions of understory versus canopy plants, and in P. ilicifolia this difference was highly significant ( $t$-test, $P<0.001$ ). Dirca occidentalis had a distinctly bimodal distribution of PDI values, reflecting its primary distribution on cool, north-facing slopes with a secondary peak due to local concentrations on several hilltops (Fig. 1).

\section{Trait distributions}

Among the 22 shrub species, leaf size varied by 3 orders of magnitude, while SLA varied by $<1$ order of magni-

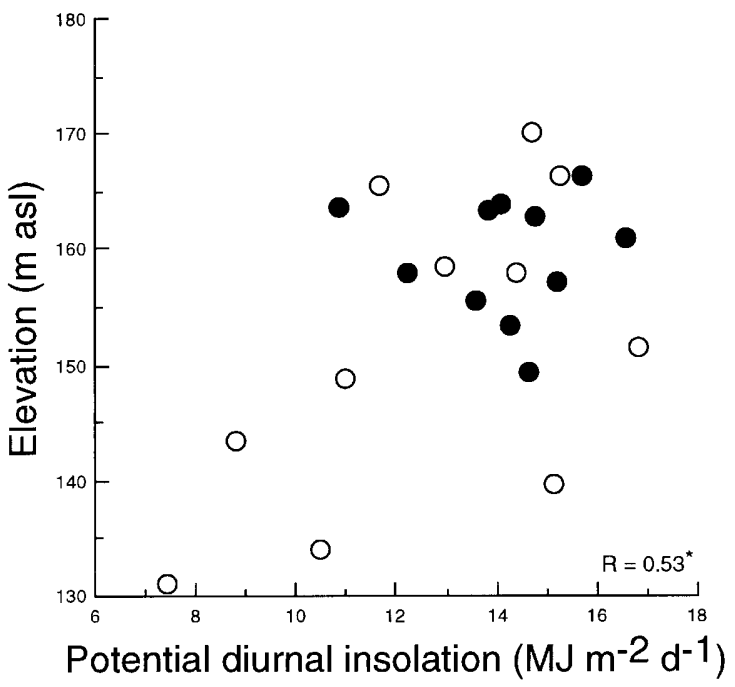

Fig. 2 Scatterplot of mean position of each species along gradients of PDI and elevation (see Fig. 1). Open symbols Deciduous species; closed symbols evergreen species. Significance values for correlations and regressions in this and following figures: $* P<0.05 ; * * P<0.01 ; * * * P<0.001$ tude (Fig. 3A). The mean PDI value for plants used to sample leaf traits was strongly correlated with the average value observed along the transects $(R=0.73$, $n=18, P<0.001)$, suggesting that our SLA values reflect the values that would have been observed for these species along the transects. SLA was significantly greater in deciduous species than in evergreens ( $t$-test, $P=0.002$; Fig. 3A), but leaf size was not significantly different between these two groups. SLA and leaf size were weakly correlated $(R=0.30, \mathrm{NS})$, indicating a non-significant trend for larger-leaved species to have higher leaf area per unit mass (i.e., thinner or less dense leaves; Fig. 3A). However, this trend was absent if A. fasciculatum (which has needle-like leaves) was excluded $(R=0.07)$.

For individual species, there was a significant negative regression of SLA versus the mean location along the insolation gradient of each species $\left(r^{2}=0.265\right.$, Fig. 4B). This decline was due to an increase in the representation of evergreen species at high PDI values, and to a correlation between SLA and PDI for evergreens. SLA of deciduous species did not change across the gradient. Leaf size showed a negative trend with increasing mean insolation, but the relationship was not significant (Fig. 4A). There was a greater range of leaf size for species with high mean insolation values, due to a decrease in minimum leaf size with little change in the maximum across the gradient (Fig. 4A). This increased disparity was evident for both evergreen and deciduous species. SLA was negatively correlated with mean cover $\left(r^{2}=0.25, n=22, P=0.018\right)$, indicating that low SLA species tended to be dominant at a local scale. There were

Fig. 3A, B Relationships between specific leaf area (SLA) and leaf size (lamina area) at the species level and community level. A Scatterplot of SLA versus leaf size for the 22 shrub species in this study. Open symbols Deciduous species; closed symbols evergreen species. Excluding Adenostoma fasciculatum (Af) the correlation was much weaker $(R=0.07)$. B Scatterplot of average SLA versus average leaf size at the community level. Each point represents the average value based on species presence/absence data, for all plots in each of 13 levels of insolation; scale is the same as in A. Significance values listed in Fig. 2 legend
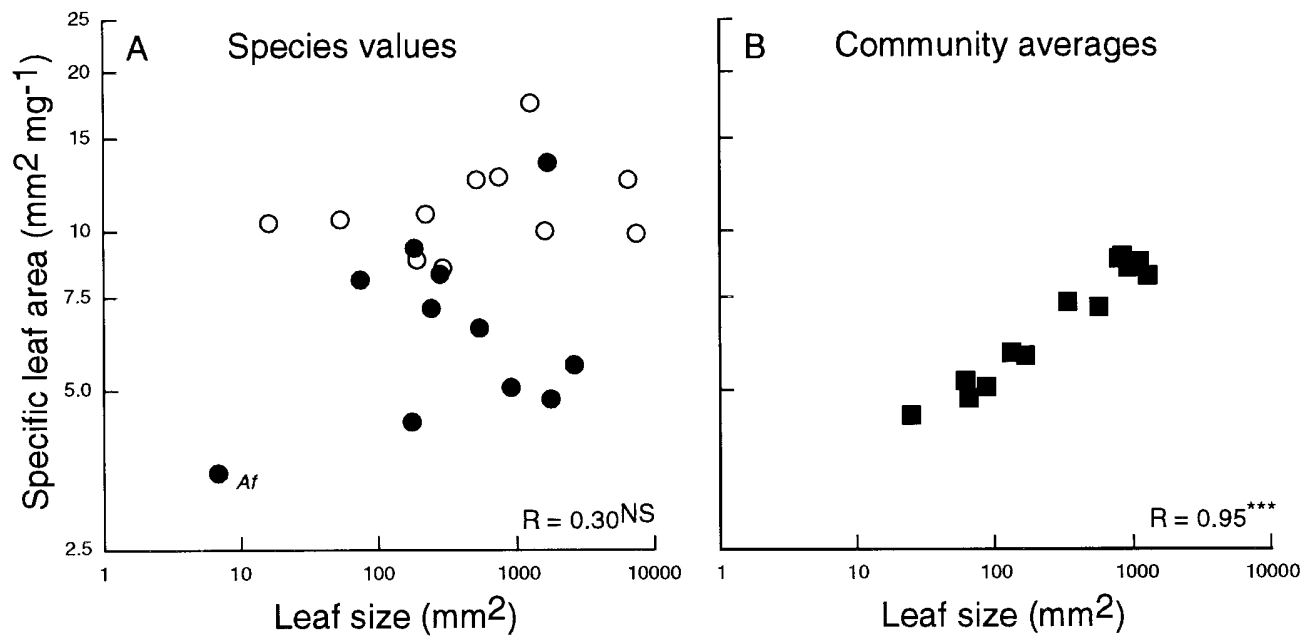
Fig. 4A-D Relationships between potential diurnal insolation (PDI) and leaf form based on species values and community averages. A, B Trait values and mean position along the insolation gradient for individual species. Open symbols Deciduous species; closed symbols evergreen species. The larger symbols are for the five species with highest frequency of occurrence (Adenostoma fasciculatum, Ceanothus cuneatus, Heteromeles arbutifolia, Prunus ilicifolia, Toxicodendron diversilobum; see Table 1). C, D Average trait values for plots at different insolation levels, based on species presence/absence (open triangles) or relative abundance (filled squares). Significance values listed in Fig. 2 legend. In $\mathbf{C}$, error bars $( \pm 1 \mathrm{SD})$ are shown for lowest and highest insolation levels to illustrate the increase in variance in leaf size across the gradient (see text)
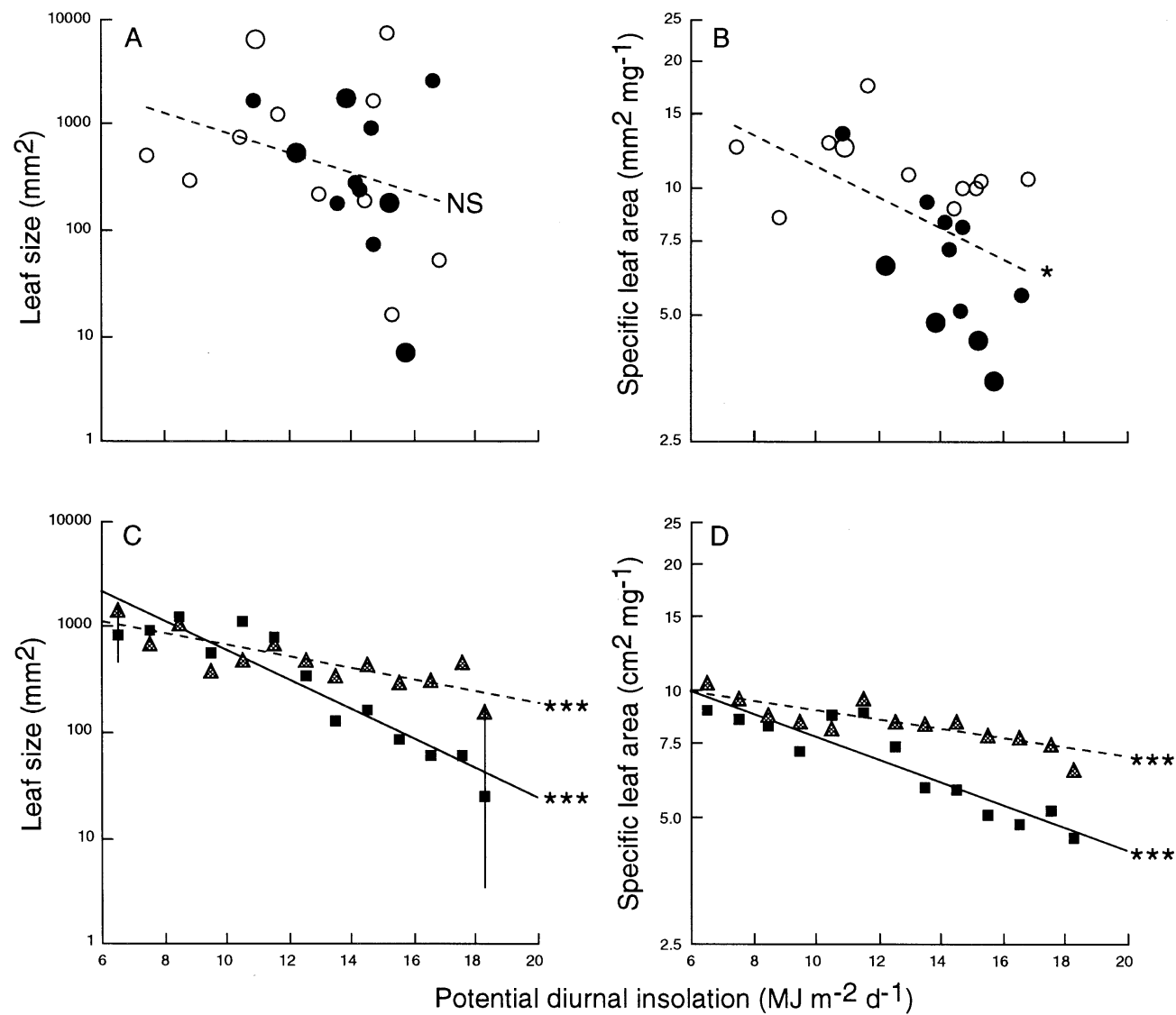

no significant relationships between leaf traits and relative frequency of occurrence ('Freq', Table 1), or measures of niche breadth along the insolation gradient (results not shown).

At the community level, the average values for leaf size and SLA declined significantly with increasing PDI $\left(r^{2}=0.88\right.$ and 0.89 , respectively; Fig. 4C, D). In both cases, there was a steeper gradient when average trait values were weighted by species relative cover, compared to unweighted presence/absence data. The steeper slopes reflect the characteristics of the dominant species: A. fasciculatum and Ceanothus cuneatus (small leaves and low SLA) on south-facing slopes and P. ilicifolia, Heteromeles arbutifolia and Toxicodendron diversilobum (intermediate to large leaf size and SLA) on north-facing slopes (see larger points in Fig. 4A, B). There was also a significant increase in the standard deviation of leaf size with increasing PDI $\left(r^{2}=0.70, P<0.001\right.$; see selected error bars in Fig. 4C). There were no significant relationships between average trait values and elevation, across individual species or community level averages.

There was a very strong correlation between community level averages for leaf size and SLA, based on species relative abundance data (Fig. 3B). This strong association reflects the parallel shifts in the two traits across the gradient (Fig. 4C, D). There was a striking contrast between this strong relationship in the community level averages, and the lack of correlation at the species level (Fig. 3B vs Fig. 3A). This discrepancy results from the effects of averaging trait values. Weak trends in each trait at the species level result in steady shifts in the averages as species replace each other along the gradient. This turnover is accompanied by an increase in the frequency of small-leaved species and low SLA species, even though these may be represented by different taxa.

\section{Intraspecific variation}

In both the primary SLA data and the 'herbivory' study, the average level of intraspecific variation in SLA was approximately 2 -fold (0.3 log units), compared to 5-fold interspecific variation (0.75 log units). Intraspecific SLA variation was not significantly associated with PDI values for the location of each plant in either study (ANCOVA with species as fixed factor and PDI as covariate; primary data: $F_{1,190}=2.39, \quad P>0.1$; herbivory study: $\left.F_{1.81}=1.69, P>0.1\right)$. In contrast, in an independent sample of $P$. ilicifolia, mean SLA of sun leaves was 4.25 and $6.21 \mathrm{~mm}^{2} \mathrm{mg}^{-1}$ at the high and low extremes of the insolation gradient (16.5-17.5 vs 6.5-8.5 $\left.\mathrm{MJ} \mathrm{m}^{-2} \mathrm{day}^{-1}\right)$, and the difference was highly significant. 


\section{Discussion}

In this study we quantified solar exposure at a local scale using a GIS model of PDI, and examined the distribution of chaparral shrub species along gradients of elevation and insolation. Our results confirm that exposure on north- versus south-facing slopes was the most important topographic factor associated with small-scale species distributions, followed by variation in elevation (see Cooper 1922; Boyko 1947; Parsons 1976; Armesto and Martínez 1978). Leaf traits were significantly associated with species distributions on the insolation gradient, but not with elevation. In analyses of community level averages and individual species, SLA declined with increasing insolation indicating that species with thicker and/or denser leaves preferentially occupied more exposed, south-facing slopes. There was also a negative but nonsignificant trend in leaf size of individual species in relation to their distribution along the insolation gradient. At the community level, this trend was reflected as a highly significant shift in the average leaf size of species in plots occupying different positions on the gradient. These results demonstrate that shifts observed in average leaf characteristics at a community level may be based on very weak relationships between leaf traits and individual species distributions. Even more striking is the discrepancy between the two levels of analysis in the correlations between the two traits. At the community level, the parallel shifts in mean leaf size and mean SLA led to a very strong correlation between the two. Yet, for the 22 shrub species in this community these traits were not significantly correlated. The contrast between these two levels of analysis apparently results from the averaging of two independent but parallel trends. As expected from statistical sampling considerations, the trends in the averages will exhibit more regular patterns than the underlying distribution of species values.

As discussed in the Introduction, the effects of insolation are multifaceted and we did not attempt to separate the effects of air and soil temperatures, soil moisture and nutrient availability on species distributions. The reduction in average leaf size and SLA with increasing exposure is consistent with the general view that these two traits are part of a suite of characteristics associated with stress tolerance, in particular the stress tolerant, evergreen strategy of sclerophyllous shrubs in the chaparral (Mooney and Dunn 1970a; Parsons 1976). However, several aspects of our results suggest that this interpretation is not sufficient to explain these patterns. First, the lack of correlation between leaf size and SLA at the species level suggests that the two traits are associated with different environmental factors or ecophysiological strategies. The concept of sclerophylly ('leathery leaf') is related to the thickness and texture of leaves, and in a recent study Edwards et al. (2000) found that SLA was well correlated with subjective assessments of the degree of sclerophylly (low SLA corresponds to more sclerophyllous) (see Specht and Rundel 1990). SLA is negatively correlated with leaf life span and leaves with low
SLA and long life span have lower assimilation rates (per unit mass) (Reich et al. 1997). However, greater longevity promotes nutrient retention, enhancing longterm photosynthetic nitrogen-use efficiency (Field 1988; Chapin et al. 1993). Low SLA is also associated with thicker cuticles in chaparral plants (Cooper 1922), reducing water loss and susceptibility to desiccation. In this study, we did not quantify soil moisture and nutrient availability along the insolation gradient, so the potential importance of low SLA with respect to nutrient versus water stress cannot be assessed (see Westman 1983; Cunningham et al. 1999).

In contrast, the most important direct effect of small leaf size (specifically, leaf width) is the reduction in boundary layer resistance (Gates 1965). This enhances convective heat loss, facilitating maintenance of leaf energy balance, and improving water use efficiency under summer conditions (Parkhurst and Loucks 1972; Givnish and Vermeij 1976; Miller and Stoner 1979). Low SLA and small leaf size are coupled in some species, in particular the chaparral dominant Adenostoma fasciculatum, but very small leaves are also observed in deciduous plants such as Lotus scoparius and Artemisia californica. Conversely, relatively large leaves are found in evergreen sclerophylls such as Arbutus mensiezii, Heteromeles arbutifolia and Eriodictyon californicum (Table 1). Compared to plants in some other ecosystems, all of the chaparral sclerophylls may have relatively small leaves and low SLA. However, it is still important to recognize that within this community the two traits are not correlated at the species level, though they both exhibit parallel shifts across the insolation gradient. Fonseca et al. (2000) recently examined shifts in SLA and leaf size along independent gradients of precipitation and nutrient availability. They also observed parallel changes in both traits at the community level, but found that they were only weakly correlated across species (also see Ackerly and Reich 1999). Thus it appears that the results we have reported are not restricted to our chaparral community.

The second result which emerges from the analysis of species traits and distributions is that the trend towards smaller leaves on exposed slopes was due to a reduction in minimum leaf size, not to an overall shift from larger to smaller leaves (Fig. 4A). Species with large leaves are observed across the entire insolation gradient, but smallleaved species are concentrated at the high exposure end on south-facing slopes. The change in mean leaf size with exposure is commonly interpreted in terms of the advantages of small leaves for maintaining leaf temperatures in hot environments. However, the distribution observed here suggests that the shift in mean leaf size is due to the absence of small-leaved plants on north-facing slopes. The large-leaved species on south-facing slopes include both evergreen and deciduous species which exhibit high predawn water potentials throughout the dry season, suggesting that they have deep roots (e.g., Eriodictyon californicum and Sambucus mexicana), and drought-deciduous species that drop their leaves and avoid summer temperatures and water stress (e.g., 
Lepechinia calycina) (Mooney 1982; D. Ackerly, unpublished data). The small-leaved species on south-facing slopes include drought tolerant sclerophylls (e.g., Adenostoma fasciculatum and Ceanothus cuneatus), which dominate these portions of the community, and droughtdeciduous species (e.g., Lotus scoparius and Artemisia californica). The absence of small-leaved species on less exposed, north-facing slopes, may reflect greater competition for light and the lower efficiency of small leaves for light capture and shading of neighbors. Many of the species occupying north-facing slopes are "fire-persisters" which lack seed dormancy and only regenerate from seed in the mesic understory during fire-free intervals (e.g., H. arbutifolia, P. ilicifolia; see Keeley 1992). Establishment in this relatively shaded environment may be enhanced by large leaves, but experimental studies to test this hypothesis are needed.

Quantitative studies of variation in plant traits along environmental gradients have played a critical role in testing adaptive hypotheses for the functional significance of plant form. Correlations between leaf attributes and climate in extant plant communities have also been widely used for paleoclimatic reconstruction (Wolfe 1994). Most of this research has been based on the frequency of different attributes (e.g., C3 vs C4, evergreen vs deciduous, toothed vs entire leaf margins) or average trait values (e.g., leaf size) in contrasting communities or varying sites within communities. This study suggests that such community level analyses may lead to overestimates of the strength of adaptive relationships in comparison with analyses which focus on distributions and traits at the level of individual species. We found that there may be shifts in the average values for two traits, in this case leaf size and SLA, at the community level, even though the two traits are not significantly correlated across species. Species level analyses also emphasize that apparent shifts in mean trait values may actually represent a change in variance, with decreasing minimum or increasing maximum values across an environment gradient. We observed such an increase in the variation in leaf size among species of south-facing slopes, suggesting a greater diversity of water use and leaf energy balance strategies under more exposed conditions. This pattern may be mirrored in the diversity of sun/shade regeneration strategies in light-limited forest environments, the array of phenological and physiological water use strategies in deserts, and the range of nutrient conservation and acquisition strategies in bogs and other chronic, low nutrient environments. Further research addressing this hypothesis should focus on the relationship between plant form and resource acquisition strategies, the variation of strategies within communities, and the shifts in minimum and maximum values of functional traits along climatic gradients.

Acknowledgements We thank K.A. Preston and K. Van Kuren for assistance with field work and data analysis, and A. Weiss for GIS support. M. Martinez-Ramos, H.A. Mooney, W.J. Platt and several anonymous reviewers provided valuable comments on the manuscript. The GIS base map for Jasper Ridge Biological Pre- serve was created by A. Weiss and P.S. Cohen. This study was funded in part by grants to D.D.A. from the Stanford University Office of Technology Licensing and a Terman Fellowship from Stanford University. The manuscript was completed while the first author was on leave at the Jepson Herbarium, University of California, Berkeley.

\section{References}

Ackerly DD, Reich PB (1999) Convergence and correlations among leaf size and function in seed plants: a comparative test using independent contrasts. Am J Bot 86:1272-1281

Armesto JJ, Martínez JA (1978) Relations between vegetation structure and slope aspect in the Mediterranean region of Chile. J Ecol 66:881-889

Austin MP, Nicholls AO, Margules CR (1990) Measurement of the realized qualitative niche: environmental niches of five Eucalyptus species. Ecol Monogr 60:161-177

Box EO (1981) Macroclimate and plant forms: an introduction to predictive modeling in phytogeography. Junk, The Hague

Boyko H (1947) On the role of plants as quantitative climate indicators and the geo-ecological law of distribution. J Ecol 35:138-157

Chapin FS III, Autumn K, Pugnaire F (1993) Evolution of suites of traits in response to environmental stress. Am Nat 142:S78S92

Cooper WS (1922) The broad-sclerophyll vegetation of California: an ecological study of the chaparral and its related communities. Publication 319, Carnegie Institution of Washington, Washington, D.C.

Cunningham SA, Summerhayes BA, Westoby M (1999) Evolutionary divergences in leaf structure and chemistry, comparing rainfall and soil nutrient gradients. Ecol Monogr 69:569-588

Dolph G, Dilcher D (1980) Variation in leaf size with respect to climate in the tropics of the western hemisphere. Bull Torrey Bot Club 107:154-162

Edwards C, Read J, Sanson G (2000) Characterising sclerophylly: some mechanical properties of leaves from heath and forest. Oecologia 123:158-167

Ehleringer J, Mooney HA, Gulmon SL, Rundel PW (1981) Parallel evolution of leaf pubescence in Encelia in coastal deserts of North and South America. Oecologia 49:38-41

Field CB (1988) On the role of photosynthetic responses in constraining the habitat distribution of rainforest plants. Aust $\mathbf{J}$ Plant Physiol 15:343-58

Fonseca CR, Overton JM, Collins B, Westoby M (2000) Shifts in trait-combinations along rainfall and phosphorous gradients. J Ecol 88:964-977

Franklin J (1998) Predicting the distribution of shrub species in southern California from climate and terrain-derived variables. J Veg Sci 9:733-748

Gates DM (1965) Energy, plants, and ecology. Ecology 46:1-13

Geiger R (1965) The climate near the ground. Harvard University Press, Cambridge, Mass.

Givnish TJ (1984) Leaf and canopy adaptations in tropical forests. In: Medina E, Mooney HA, Vázquez-Yanes C (eds) Physiological ecology of plants of the wet tropics. Junk, The Hague, pp 51-84

Givnish TJ, Vermeij GJ (1976) Sizes and shapes of liane leaves. Am Nat 110:743-778

Grubb P (1998) A reassessment of the strategies of plants which cope with shortages of resources. Perspect Plant Ecol Evol $1: 3-31$

Hamann O (1979) On climatic conditions, vegetation types, and leaf size in the Galápagos Islands. Biotropica 11:101-122

Hetrick WA, Rich PM, Barnes FJ, Weiss SB (1993) GIS-based solar radiation flux models. Am Soc Photo Rem Sens Tech Pap 3:132-143

Hickman JC (1993) The Jepson manual: higher plants of California. University of California Press, Berkeley, Calif. 
Jongman RHG, Ter Braak CJF, Van Tongeren OFR (1995) Data analysis in community and landscape ecology, new edn. Cambridge University Press, Cambridge

Keeley JE (1992) Recruitment of seedlings and vegetative sprouts in unburned chaparral. Ecology 73:1194-1208

Keeley JE, Fotheringham CJ, Morais M (1999) Reexamining fire suppression impacts on brushland fire regimes. Science 284:1829-1832

Kutiel P (1997) Spatial and temporal heterogeneity of species diversity in a Mediterranean ecosystem following fire. Int $\mathbf{J}$ Wildl Fire 7:307-315

Mabry C, Ackerly DD, Gerhardt F (2000) Landscape and specieslevel distribution of morphological and life history traits in a temperate woodland flora. J Veg Sci 11:213-224

Martínez JA, Armesto JJ (1983) Ecophysiological plasticity and habitat distribution in 3 evergreen sclerophyllous shrubs of the Chilean matorral. Acta Oecol Plant 4:211-219

Miller EH Jr (1947) Growth and environmental conditions in southern California chaparral. Am Midl Nat 37:379-420

Miller P, Stoner W (1979) Canopy structure and environmental interactions. In: Solbrig OT, Jain S, Johnson GB, Raven PH (eds) Topics in plant population biology. Columbia University Press, New York, pp 428-460

Miller PC (1979) Quantitative plant ecology. In: Horn DJ, Stairs GR, Mitchell RD (eds) Analysis of ecological systems. Ohio State University Press, Columbus, pp 179-231

Miller PC, Poole DK, Miller PM (1983) The influence of annual precipitation, topography, and vegetative cover on soil moisture and summer drought in Southern California. Oecologia 56:385-391

Mooney HA (1977) Convergent evolution in California and Chile: Mediterranean climate ecosystems. Dowden, Hutchinson and Ross, Stroudsberg, $\mathrm{Pa}$.

Mooney HA (1982) Habitat, plant form, and plant water relations in Mediterranean-climate regions. Ecol Mediterr V:481-488

Mooney HA, Dunn EL (1970a) Convergent evolution of Mediterranean-climate evergreen sclerophyllous shrubs. Evolution 24:292-303

Mooney HA, Dunn EL (1970b) Photosynthetic systems of Mediterranean-climate shrubs and trees of California and Chile. Am Nat 104:447-453

Mooney HA, Dunn EL, Shropshire F, Song L (1970) Vegetation comparisons between the Mediterranean climatic areas of California and Chile. Flora 159:480-496

$\mathrm{Ng}$ E, Miller PC (1980) Soil moisture relations in the southern California chaparral. Ecology 61:98-107

Nobel PS, Linton MJ (1997) Frequencies, microclimate and root properties for three codominant perennials in the Northwestern
Sonoran desert on north- vs. south-facing slopes. Ann Bot 80:731-739

Parkhurst D, Loucks O (1972) Optimal leaf size in relation to environment. J Ecol 60:505-537

Parsons DJ (1976) Vegetation structure in the Mediterranean scrub communities of California and Chile. J Ecol 64:435-447

Parsons DJ, Moldenke AR (1975) Convergence in vegetation structure along analogous climatic gradients in Calfornia and Chile. Ecology 56:950-957

Poole DK, Miller PC (1981) The distribution of plant water stress and vegetation characteristics in Southern California chaparral. Am Midl Nat 105:32-43

Reich PB, Walters MB, Ellsworth DS (1997) From tropics to tundra: global convergence in plant functioning. Proc Ntl Acad Sci USA 94:13730-13734

Schimper AFW (1903) Plant geography upon a physiological basis. Clarendon Press, Oxford

Skarpe C (1996) Plant functional types and climate in a southern African savanna. J Veg Sci 7:397-404

Specht RL (1969) A comparison of the sclerophyllous vegetation characteristic of Mediterranean type climates in France, California and southern Australia. I. Structure, morphology, and succession. Aust J Bot 17:277-292

Specht R, Rundel P (1990) Sclerophylly and foliar nutrient status of mediterranean-climate plant communities in southern Australia. Aust J Bot 38:459-474

Ter Braak CJF, Smilauer P (1998) CANOCO reference manual and user's guide to Canoco for Windows: software for Canonical Community Ordination (version 4). Microcomputer Power, Ithaca, N.Y.

Weiss SB, Murphy DD, Ehrlich PR, Metzler CF (1993) Adult emergence phenology in checkerspot butterflies: the effects of macroclimate, topoclimate, and population history. Oecologia 96:261-270

Westman WE (1981) Factors influencing the distribution of species of California coastal sage scrub. Ecology 62:439-455

Westman WE (1983) Plant community structure - spatial partitioning of resources. In: Kruger FJ, Mitchell DT, Jarvis JUM (eds) Mediterranean-type ecosystems: the role of nutrients. Springer, Berlin Heidelberg New York, pp 417-445

Westman WE (1991) Measuring realized niche spaces: climatic response of chaparral and coastal sage scrub. Ecology 72:1678-1684

Whittaker RH (1967) Gradient analysis of vegetation. Biol Rev 42:207-264

Wolfe JA (1994) Tertiary climatic changes at middle latitudes of western North America. Palaeogeogr Palaeoclim Palaeoecol 108:195-205 